\title{
EVALUASI WEBSITE E-COMMERCE MENGGUNAKAN METODE EXTENDED WEB ASSESSMENT METHOD (EWAM) (Studi kasus abadigrosir.com)
}

\author{
Tubagus Riko Rivanthio, S.Kom., M.Kom. \\ Dosen Prodi Manajemen Informatika \\ Politeknik LP3I Bandung \\ Email: riko_rivanthio@yahoo.com
}

\begin{abstract}
Abstrak: Penelitian ini bertujuan untuk mengetahui tingkat kepuasan konsumen terhadap layanan website e-commerce abadigrosir.com dengan menggunakan metode Extended Web Assessment Method (EWAM). Metode Ewam adalah suatu alat evaluasi website yang terdiri dari market focus, subjective (persepsi kualitas pelanggan) dan attribute spesific. Metode EWAM ini menitik beratkan pada tiga kriteria penilaian, yang terdiri dari Usefullnes (Kemudahan), Easy Of Use (mudah digunakan), Trust (Kepercayaan). Hasil penilaian konsumen menggunakan metode EWAM adalah konsumen memberikan penilaian yang baik untuk kriteria kegunaan dari web abadigrosir.com, dengan nilai rata-ratanya yaitu sebanyak 51\% yang menyatakan baik, dan 16\% menyatakan sangat baik. Untuk kriteria mudah digunakan, konsumen memberikan penilaian yang baik dengan nilai rata-ratanya yaitu sebanyak $50 \%$ yang menyatakan baik, dan 10\% menyatakan cukup. Sedangkan kiteria kepercayaan, konsumen memberikan penilaian yang dominan, dimana konsumen sangat mempercayai legalitas dari web abadigrosir.com yaitu sebanyak 53\% konsumen menyatakan baik, dan $40 \%$ menyatakan sangat baik.
\end{abstract}

Kata Kunci: Website, E-Commerce, EWAM

\section{Pendahuluan}

\subsection{Latar Belakang Masalah}

Pada saat ini banyak sekali para penjual produk maupun jasa menggunakan website ecommerce dalam melakukan penjualan produk maupun jasa yang mereka tawarkan. Perkembangan website e-commerce saat ini sangatlah pesat. Saat ini website e-commerce merupakan alat yang wajib dalam melakukan transaksi penjualan, karena dengan adanya website e-commerce dapat mendongkrak pendapatan penjualan. Seperti telah diketahui bahwa dengan adanya website e-commerce, maka jangkauan customer bisa lebih luas lagi dan tidak mengenal batas waktu. Berbeda ketika melakukan metode penjualan tradisional yaitu menjual produk di toko offline, memiliki keterbatasan waktu dan jangkauan customer.

Dengan banyaknya website e-commerce yang bermunculan maka pelaku usaha penjualan berlomba-lomba untuk menarik customer agar mau melakukan pembelian produk yang 
ditawarkan pada website e-commerce. Untuk menarik perhatian customer maka website e-commerce haruslah memiliki penampilan dan fitur-fitur layanan yang dapat menarik perhatian customer. Website yang memiliki fitur-fitur dan tampilan yang menarik biasanya website yang dapat bertahalan lama didalam persaingan dunia e-commerce. Namun tidak sedikit web e-commerce yang dapat bertahan dengan persaingan yang terjadi. Hal ini disebabkan website tersebut kurang memiliki tampilan yang baik dan fiturfitur layanan yang tidak sesuai keinginan customer. Maka dari itu agar website ecommerce dapat bertahan pada persiangan di dunia e-commerce, maka perlu dilakukan evaluasi terhadap website e-commerce. Untuk melakukan evaluasi website dapat menggunakan tools evaluasi website. Terdapat banyak tools yang dapat digunakan untuk mengevaluasi website, salah satunya adalah Metode Extended Web Assessment Method (EWAM). EWAM adalah suatu alat evaluasi yang secara spesifik dibuat untuk menilai aplikasi-aplikasi e-commerce. EWAM sebuah metode yang didasarkan kepada kisi evaluasi mencakup sekumpulan kriteria untuk menilai kualitas dan keberhasilan aplikasiaplikasi e-commerce yang fokus kepada perspektif konsumen dan fitur-fitur yang spesifik dari internet sebagai media (Susilo, 2010).

Pada penelitian ini akan melakukan evaluasi terhadap web e-commerce abadigrosir.com. Abadigrosir.com merupakan web ecommerce yang menyediakan penjualan pakaian. Dalam upaya meningkatkan penjualan abadigrosir.com beruasa memberikan pelayanan yang terbaik kepada pelanggan. Salah satu upaya untuk meningkatkan pelayanan yang terbaik kepada pelanggan adalah memberikan kualitas web yang terbaik kepada pelanggan, terlebih lagi bahwa abadigrosir sangat mengandalkan web ecommerce-nya dalam melakukan penjualan.

Maksud dari evaluasi web abadigrosir.com ini adalah untuk menilai kualitas dan keberhasilan web abadigrosir.com sebagai web ecommerce yang dapat dipercaya oleh konsumen. Kepercayaan konsumen adalah hal yang terpenting pada keberadaan web ecommerce abadigorsir.com. Karena dengan kepercayaan konsumen terhadap web abadigrosir.com maka konsumen akan melakukan pembelian lagi di abadigrosir.com. Sehingga dengan semakin banyak transaksi yang dilakukan oleh konsumen maka penjualan di abadigrosir.com akan meningkat dan berdampak pada peningkatan omset.

Selain dari penilaian kepercayaan konsumen terhadap web abadigrosir.com. Kemudahan penggunaan dan fungsi dari web ecommerce abadi grosir.com juga harus dievaluasi. Evaluasi kemudahan penggunaan dan fungsi ini bertujuan untuk mengetahui sejauh mana konsumen merasa nyaman dalam bertransaksi di web abadigrosir.com.

Kenyamanan diakui sebagai faktor yang mendorong keputusan konsumen untuk membeli secara online di rumah. Kenyamanan ini adalah mengenai waktu, ruang, dan penghematan upaya yang dilakukan konsumen. Tidak ada kerumunan orang yang berbelanja atau mengantri dan tidak ada kemacetan lalu lintas atau kepadatan tempat parkir sehingga dapat membantu untuk menghemat dan mempersingkat waktu (Suki, 2005).

Berdasarkan teori tersebut dapat diambil kesimpulan jika web abadigrosir.com memberikan kemudahan-kemudahan dalam bertransaksi pada web, maka dapat memberikan kenyamanan terhadap konsumen sehingga konsumen akan sering bertransaksi di web abadigrosir.com. 
Berdasarkan paparan pada beberapa paragraf sebelumnya maka penelitian akan dilakukan evaluasi terhadap web ecommerce abadigrosir.com menggunakan metode EWAM (Extended Web Assessment Method) dengan tujuan untuk mengetahui tingkat kepercayaan dan kenyamanan konsumen dalam bertransaksi di web ecommerce abadigrosir.com.

\subsection{Rumusan Masalah}

Pada latar belakang masalah telah diuraikan tentang permasalahan pada web abadigrosir.com, sehingga untuk rumusan masalahnya adalah bagaimana tingkat kenyaman dan kepercayaan konsumen dalam bertransaksi pada web ecommerce abadigrosir.com.

\section{Landasan Teori}

\subsection{E-Commerce}

\section{a. Definisi E-Commerce}

Istilah E-Commerce mulai muncul ditahun 1990-an melalui adanya inisiatif untuk mengubah paradigma transaksi jual beli dan pembayaran dari cara konvensional ke dalam bentuk digital elektronik berbasiskan computer dan jaringan internet. Terdapat beberapa buah definisi mengenai E-Commece seperti berikut ini : (Pratama, 2015)

1. Menurut Kim dan Moon tahun 1998 : E-Commerce dalah proses untuk mengantarkan informasi, produk, layanan, dan proses pembayaran, melalui kabel telepon, koneksi internet, dan akses digital lainnya.

2. Baourakis, Kourgiantakis, dan Migdalas tahun 2002 : E-Commerce merupakan bentuk perdagangan melalui jaringan internet.

3. Quayle, tahun 2002, E-Commerce adalah bentuk pertukaran data elektronik atau electronic data interchange (EDI) yang melibatkan penjual dan pembeli melalui perangkat mobile, email, perangkat terhubung mobile, didalam jaringan internet dan intranet.

4. Chafey, tahun 2007, E-Commerce adalah semua bentuk proses pertukaran informasi antara organisasi dan stakeholder berbasiskan media elektronik yang terhubung ke internet.

b. Informasi Komponen penting dalan E-Commerce

E-Commerce memiliki alur kegiatan secara umum yang melibatkan empat komponen. Keempat komponen itu meliputi : (Pratama, 2015)

1. Penjual : Pihak penjual dapat berupa pemilik took online bersangkutan atau sejumlah pelaku usaha (apabila e-commerce dalam bentuk multi took didalamnya atau multi kepemilikan).

2. Konsumen : Merupakan pihak yang memegang peran penting di dalam jalannya sebuah E-Cmmerce. Sebagamana pasar dan transaksi langsung didunia nyata, pada E-Commerce pun konsumen adalah raja. 
3. Teknologi : Teknologi mencakup semua teknologi informasi terkini yang digunakan di dalamnnya E-Commerce. Dimulainya dari teknilogi web (misalkan PHP dan MySQL), aplikasi mobile (misalkan dengan protocol SSL), dukungan cloud computing, ERP (Enterprise Resource Planning), CRM (Custom Relationship Management), POS (Point of Sale) dukungan kurs mata uang dan bahasa seluruh negara di dunia. Geographic Information System (GIS), Near Field Communication (NFC) dan sebagainya.

4. Jaringan Komputer (Internet) : Hal terakhir yang tidak kalah pentingnya adalah ketersedian jaringan computer, khususnya internet, yang mampu memberikan kemudahan dalam bertransaksi anata penjual dan pembeli.

\section{c. Sistem Informasi Cara Kerja Sebuah E-Commerce}

Sebuah E-Commerce memiliki setidaknya beberapa buah poin penting didalamnya, terkait dengan proses kerjanya tersebut, beberapa poin penting itu meliputi : (Pratama, 2015)

1. Terdapat produk (barang maupun jasa) yang diperjualbelikan didalamnya, yang menjadi tawaran bagi para konsumen online yang membutuhkannya.

2. Terdapat konsumen online yang berminta dengan produk yang ditawarkan tersebut dan transaksi yang terjadi kemudian.

3. Terdapat mekanisme didalam melayani konsumen, ke dalam sebuah tatap muka aplikasi proses katalog dan etalase online, system yang menangani produk mana saja yang diambil oleh konsumen untuk dibayar (semacam keranjang belanja virtual), system yang menangani proses pembayaran secara digital (semacam kasir), hingga inventori

4. Terdapat prose pengiriman barang berdasarkan alamat yang diberikan oleh konsumen yang telah melakukan pembayaran dan disertai dengan pengecekan dari sisi penjual dan pembeli untuk proses pengiriman barang ke alamat pemesanan.

5. Penanganan masalah logistic (stok barang) pada took online atau invetori, untuk ketersediaan produk di dalam memenuhi permintaan konsumen

Dari kelima poin tersebut, system kerja sebuah e-commerce adalah adanya proses bisnis yang menangani kelima fungsi tersebut ke dalam sebuah aplikasi dengan sejumlah menu didalamnya. Dimulai dari konsumen took online atau pengunjung mengakses web ecommerce melalui browser. Kemudian website e-commerce memanfatkan database miliknya untuk menyajikan informasi kepada konsumen atau pengunjung mengenai produk-produk yang diawarkan kepada mereka. Kemudian website e-commerce juga menyiapkan fungsionalitas menu pembayaran dan pengiriman barang, apabila konsumen membeli produk yang diambil tersebut dan menginputkan alamat tujuan pengiriman pesanan. Disisi lain, terdapat tatap muka administrator. Administrtor dapat berupa petugas yang digaji untuk mengelola website e-commerce maupun pemilik toko itu sendiri.

\section{d. Empat Belas Jenis Layanan pada E-Commerce}

\section{Product Management}


2. User Managament

3. Cross sell and up sell

4. Catalog management

5. Content management

6. Order management

7. Inventory Management

8. Payment Service

9. Personalization

10. Campaign Management

11. Loyalty Management

12. Customer Service

13. Search Service

14. Reporting and Data Analysis

\subsection{Persepsi Kemudahan, Kenyamanan, dan Kepercayaan konsumen}

a. Persepsi kemudahan konsumen

Menurut (Insani, 2013) dalam jurnalnya tahun 2013, menguraikan bahwa persepsi kemudahan penggunaan adalah sejauh mana konsumen melihat suatu produk atau jasa yang baru sebagai sesuatu yang lebih baik dari penggantinya. Ini berarti bahwa di dalam system reservasi online melalui website seorang pelanggan hanya perlu melakukan beberapa klik dan mengetik data dalam waktu 5-10 menit sudah dapat memesan tiket, dibandingkan dengan sistem lama secara konvensional yang harus datang ke loket / agenagen sehingga harus melakukan banyak usaha seperti pergi ke loket yang memerlukan transportasi. Melalui website calon pembeli tiket hanya perlu berada di depan layar komputer. Kemudahan penggunaan system reservasi online ini lebih menyederhanakan langkah-langkah pemesanan tiket dari pada secara konvensional. prosedur pemesanan yang sederhana, dapat diakses tanpa batasan waktu dan pilihan prosedur pembayaran juga memainkan peranan dalam membentuk persepsi kemudahan bertransaksi online.

b. Persepsi kenyamanan konsumen

Menurut (Insani, 2013) dalam jurnalnya tahun 2013, Kenyamanan diakui sebagai factor yang mendorong keputusan konsumen untuk membeli secara online di rumah. Kenyamanan ini adalah mengenai waktu, ruang, dan penghematan upaya yang dilakukan konsumen. Tidak ada kerumunan orang yang berbelanja atau mengantri dan tidak ada kemacetan lalu lintas atau kepadatan tempat parkir sehingga dapat membantu untuk menghemat dan mempersingkat waktu Karena sifat dari website yang menyediakan informasi produk dalam weblink, konsumen dapat melakukan pendekatan terhadap produk atau apa yang mereka inginkan secara lebih mudah dengan hanya menggeser dan mengklik mouse. Proses pemesanan dalam website tentu juga lebih terasa nyaman karena adanya pengiriman pesan konfirmasi ke konsumen, termasuk rincian pemesanan atau lainnya mengenai produk melalui email. Hal ini membantu menghemat waktu dan upaya konsumen. Meskipun dalam beberapa kasus belanja online dianggap gagal apabila pemesanan memakan waktu dan rumit. Kenyamanan dalam penelitian ini merujuk pada kenyamanan mengakses website. Yale dan Venkatesh (1986) telah mengembangkan 
enam kelas kenyamanan: pemanfaatan waktu, aksesibilitas, portabilitas, ketepatan, kecekatan, dan menghindari ketidaknyamanan. Demikian pula Seider et.al (2000) menyarankan 4 jalan untuk memberikan kenyamanan, yaitu: kenyamanan akses, pencarian, possession, dan kenyamanan transaksi.

c. Extended Web Assessment Method (EWAM)

Menurut Andi Susilo dalam Tesisnya 2010, menguraikan bahwa Metode EWAN mendefinisikan sebuah kisi evaluasi dengan sekumpulan kriteria untuk menilai kualitas dan kesuksesan aplikasi-aplikasi e-commerce yang ada, di samping itu fokus yang ketat kepada perspektif konsumen. Kesuksesan dalam menerapkan penawaran produk-produk dan layanan-layanan dipertimbangkan dengan referensi kepada fitur-fitur yang spesifik dari media elektronik.

Schubert (2003) mengacu kepada analisis dan kategorisasi detail yang dilakukan oleh Totz et al. Berdasarkan artikel Totz et al., Schubert (2003) menyusun EWAM dalam kategori: (1) market focus (external visibility); (2) subjective (persepsi kualitas pelanggan); dan (3) attribute specific.

Keberhasilan sebuah aplikasi e-commerce harus sesuai dengan kebutuhan kebutuhan pengguna menurut "Perceived Usefulness", "Perceived Ease of Use", dan "Trust"

\section{Komponen-komponen EWAM}

Menurut Andi Susilo dalam Tesisnya 2010 Kriteria EWAM pertama kali ditetapkan kepada sebuah kategori kriteria ("Ease of Use", "Usefulness" atau "Trust") dan dalam tiga kategori ini dibagikan ke satu dari empat fase transaksi dari pasar elektronik (Information Phase, Agreement Phase, Settlement Phase, dan After-Sales Phase), ke komponen komunitas (Community Component), atau ke kategori "kriteria-kriteria yang perlu diseluruh fase (Final Section)". Dibandingkan dengan Web Assessment Method (WAM) yang orisinil, EWAM diperluas dengan mencakupkan After-Sales Phase dan sebuah kelompok kategori "kriteria yang cocok diseluruh fase" (Final Section). Gambar 2.8 memperlihatkan kombinasi dari WAM dengan kategori-kategori "Ease of Use" dan "Usefulness" dari Technology Acceptance Model (TAM) bersama-sama dengan kategori "Trust" yang diambil dari Theory of Reasoned Action (TRA). Dimensi sektor "1..n" mengilustrasikan perluasan dari EWAM dengan profil-profil sektor dan mempertimbangkan perbedaan kriteria individual yang penting di dalam sektor-sektor ini.

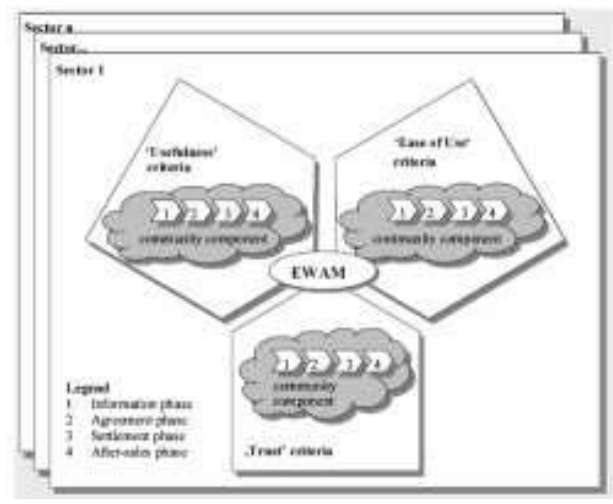

Gambar 1. Diagram Extended Web Assessment Method (EWAM) 
d. Metodologi Penelitian

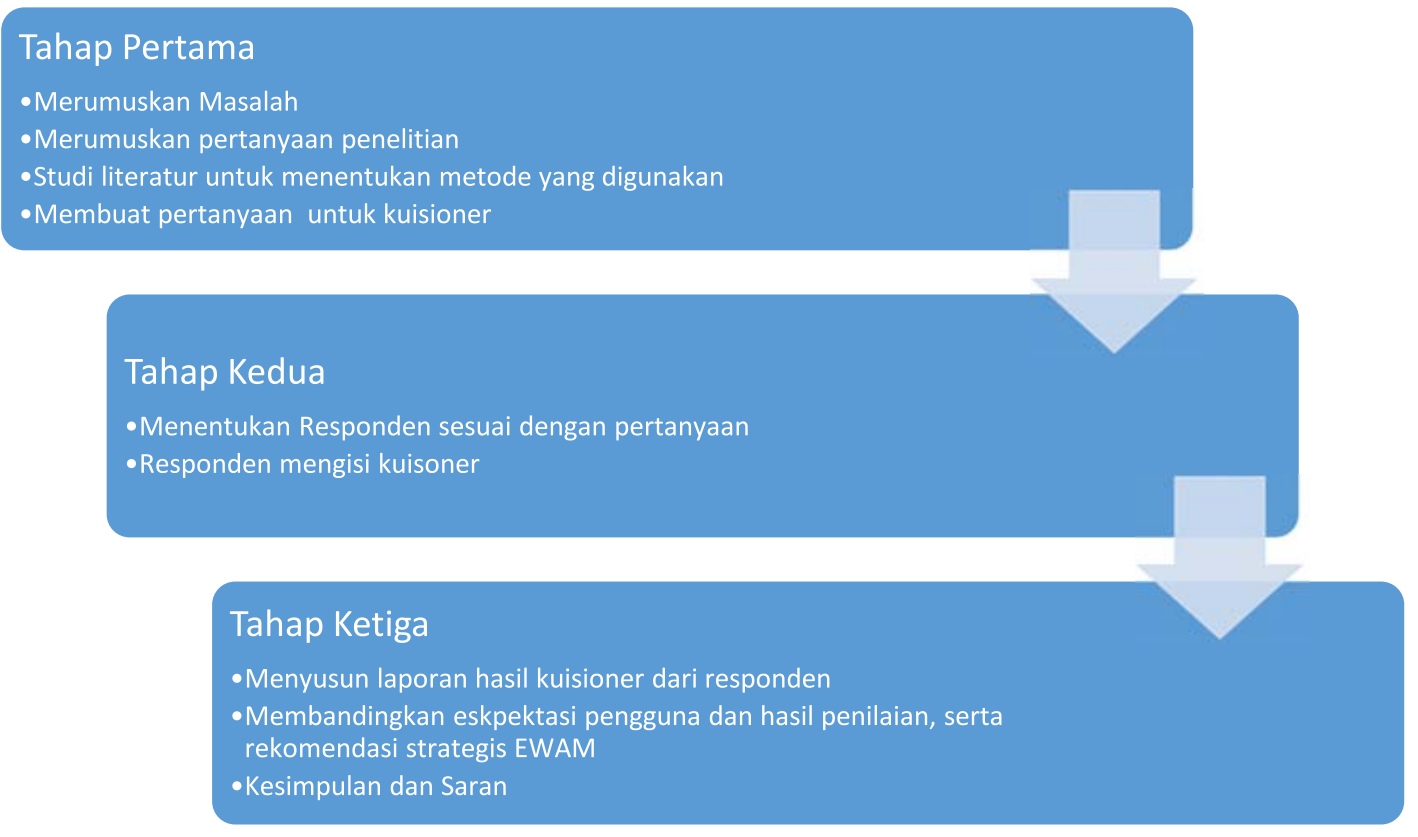

Merumuskan masalah untuk penelitian dan menyusun pertanyaan-pertanyaan terkait dengan penelitian. Melakukan studi literature tentang E-Commerce berupa definisi, alur kerja, komponen penting, jenis layanan e-commerce, teori tentang evaluasi website, teori dasar EWAM, persepi kenyaman dan kemudahan dalam menggunakan website. Setelah melakukan studi literatur selanjutnya adalah membuat pertanyaan untuk kuisioner berdasarkan dari EWAM.

\section{Strategi Penelitian}

Strategi penelitian dilakukan adalah menentukan bentuk pertanyaan untuk membuat kusioner. Menurut Yin (2003) mengindikasikan bahwa studi-studi kasus dipakai untuk membawa kepada pengertian yang lebih mendalam, pemahaman, dan pengetahuan tentang kasus tertentu yang dipilih.

Adapun strategi penentuan pertanyaan berdasarkan Yin adalah sebagai berikut :

Tabel 1. Perbedaan Riset

\begin{tabular}{|l|l|}
\hline Strategi Riset & Bentuk-bentuk Pertanyaan Riset \\
\hline Eksperimen & How/Why \\
\hline Survei & Who/What/Where/How many/How much \\
\hline Archival/Analisis & Who/What/Where/How many/How much \\
\hline History & How/Why \\
\hline Studi-studi Kasus & How/Why \\
\hline
\end{tabular}

Sumber: Diadaptasi dari Yin, 2003, pp. 5 
Menurut Andi Susilo dalam Tesisnya 2010, menguraikan bahwa Perbedaan strategi riset yang dijelaskan pada Tabel 1 oleh Yin (2003) juga relevan untuk Ilmu-ilmu Eksakta. Peneliti mengadaptasi strategi riset "Studi Kasus" yang menurut peneliti sangat tepat dipilih pada tesis ini untuk diterapkan bersama metode EWAM yang menggunakan pendekatan kuantitatif. Strategi riset studi kasus juga dipertimbangkan paling tepat dan cocok untuk penelitian evaluasi situs web per sektor. Hal ini berkaitan dengan fakta (Eshun \& Taylor, 2009) bahwa studi kasus memungkinkan bagi peneliti untuk menggali pengertian dan sebuah pemahaman mendalam terkait penelitian yang dilakukan pada tesis ini yaitu evaluasi aplikasi e-commerce pada toko buku online di Indonesia yang diwujudkan juga pada analisis kualitatif pada metode EWAM.

\section{Penentuan penguji/asesor}

Pengujian website abadigrosir.com dilakukan oleh penguji/asesor yaitu para customer yang telah melakukan transaksi pembelian barang di abadigrosir.com. Customer yang telah melakukan pembelian akan dikirimkan e-mail link kuisioner google form. Pemilihan penguji berdasarkan customer yang pernah melakukan transaksi ini diharapkan dapat menguji website abadigrosir.com secara objektif karena penguji telah mengalami pelayanan yang diberikan oleh abadigrosir.com. Setiap konsumen hanya boleh sekali melakukan pengujian, dengan cara melakukan login terlebih dahulu.

\section{e. Profil Objek Penelitian}

Abadigrosir.com merupakan website e-commerce yang bergerak dibidang penjualan pakaian, baik untuk orang dewasa maupun anak-anak. Abadigrosir.com didirikan oleh seorang entrepreneur muda yaitu Hari Budiman pada tahun 2011. Selain memiliki pelayan online, abadigrosir.com pun memiliki tempat penjualan offline sekaligus tempat penyimpanan produk-produk yang diperjualbelikan secara online, yaitu di Jl.KiaraAsri II No.3 Kel. Sukapura Kiaracondong Bandung.

Abadigrosir.com memiliki transaksi kurang lebih sekitar 300 transaksi pada setiap harinya. Dengan melakukan pelayanan transaksi selama 24 jam dan memiliki customer di berbagai kota di Indonesia.

\section{Pengumpulan dan Analisis Data}

\section{a. Pengumpulan Data}

EWAM tool merupakan kuisioner online yang dalam penelitian ini dibuat menggunakan Google Apps (Susilo, Andi; 2010). Pada penelitian ini dilakukan pembuatan kuisioner online menggunakan google form. Kuisioner ditujukan kepada konsumen yang telah melakukan transaksi. Dari sekian banyak konsumen yang melakukan transaksi dari tanggal 1 Juni - 30 Juni 2018, penulis memilih konsumen secara random sebanyak 200 konsumen untuk dijadikan sebagai penguji evaluasi website abadigrosir.com menggunakan EWAM tool. Namun dari 200 konsumen yang dikirim kuisioner melalui e-mail, terdapat 55 konsumen yang melakukan pengisian kuisioner. Setiap konsumen hanya diperbolehkan sekali melakukan pengisian kuisioner yang telah dibuat dengan cara melakukan login terlebih dahulu.

Adapun hasil pengumpulan kuisioner untuk evaluasi website abadigrosir.com adalah sebagai berikut :

1) Usia Penguji (Konsumen yang mengisi kuisioner) 
Tabel 2. Usia Penguji

\begin{tabular}{|c|c|}
\hline Usia & Jumlah \\
\hline $19-25$ & 24 \\
\hline $26-30$ & 23 \\
\hline $31-35$ & 12 \\
\hline $36-40$ & 5 \\
\hline $41-45$ & 4 \\
\hline Total & 68 \\
\hline
\end{tabular}

2) Jenis Kelamin Penguji

Tabel 3. Usia Penguji

\begin{tabular}{|c|c|}
\hline Jenis Kelamin & Jumlah \\
\hline Laki-laki & 36 \\
\hline Perempuan & 32 \\
\hline
\end{tabular}

3) Pertanyaan Fase Informasi (Information Phase)

Berikut ini adalah tabel hasil jawaban untuk Fase informasi dari konsumen yang terdiri dari 8 (delapan) pertanyaan.

Tabel 4. Hasil Jawaban Fase Informasi

\begin{tabular}{|c|c|c|c|c|c|c|c|c|c|c|}
\hline \multirow{3}{*}{ Pertanyaan } & \multicolumn{10}{|c|}{ Jawaban konsumen } \\
\hline & \multicolumn{2}{|c|}{$\begin{array}{l}\text { Sangat } \\
\text { Kurang }\end{array}$} & \multicolumn{2}{|c|}{ Kurang } & \multicolumn{2}{|c|}{ Cukup } & \multicolumn{2}{|c|}{ Baik } & \multicolumn{2}{|c|}{ Sangat Baik } \\
\hline & Jumlah & $\%$ & Jumlah & $\%$ & Jumlah & $\%$ & Jumlah & $\%$ & Jumlah & $\%$ \\
\hline $\begin{array}{l}\text { Kemudahan dalam mengakses } \\
\text { halaman/URL web (EOU01) }\end{array}$ & 0 & $0 \%$ & 3 & $4 \%$ & 9 & $13 \%$ & 41 & $60 \%$ & 15 & $22 \%$ \\
\hline $\begin{array}{l}\text { Kemudahan dalam mengakses } \\
\text { informasi produk yang } \\
\text { ditawarkan (EOU02) }\end{array}$ & 0 & $0 \%$ & 1 & $1 \%$ & 5 & $7 \%$ & 49 & $72 \%$ & 13 & $19 \%$ \\
\hline $\begin{array}{l}\text { Susunan stuktur konten/isi } \\
\text { (EOU03) }\end{array}$ & 0 & $0 \%$ & 1 & $1 \%$ & 6 & $9 \%$ & 52 & $76 \%$ & 9 & $13 \%$ \\
\hline $\begin{array}{l}\text { Kuantitas Informasi produk dan } \\
\text { lainnya (USEF01) }\end{array}$ & 0 & $0 \%$ & 1 & $1 \%$ & 5 & $7 \%$ & 55 & $81 \%$ & 7 & $10 \%$ \\
\hline $\begin{array}{l}\text { Menyampaikan harga produk } \\
\text { yang ditawarkan (USEF02) }\end{array}$ & 0 & $0 \%$ & 1 & $1 \%$ & 6 & $9 \%$ & 52 & $76 \%$ & 9 & $13 \%$ \\
\hline $\begin{array}{l}\text { Pembundelan produk-produk } \\
\text { dan layanan-layanan (USEF03) }\end{array}$ & 0 & $0 \%$ & 1 & $1 \%$ & 6 & $9 \%$ & 53 & $78 \%$ & 8 & $12 \%$ \\
\hline $\begin{array}{l}\text { Sistem-sistem rekomendasi } \\
\text { (USEF04) }\end{array}$ & 0 & $0 \%$ & 2 & $3 \%$ & 6 & $9 \%$ & 53 & $78 \%$ & 7 & $10 \%$ \\
\hline
\end{tabular}




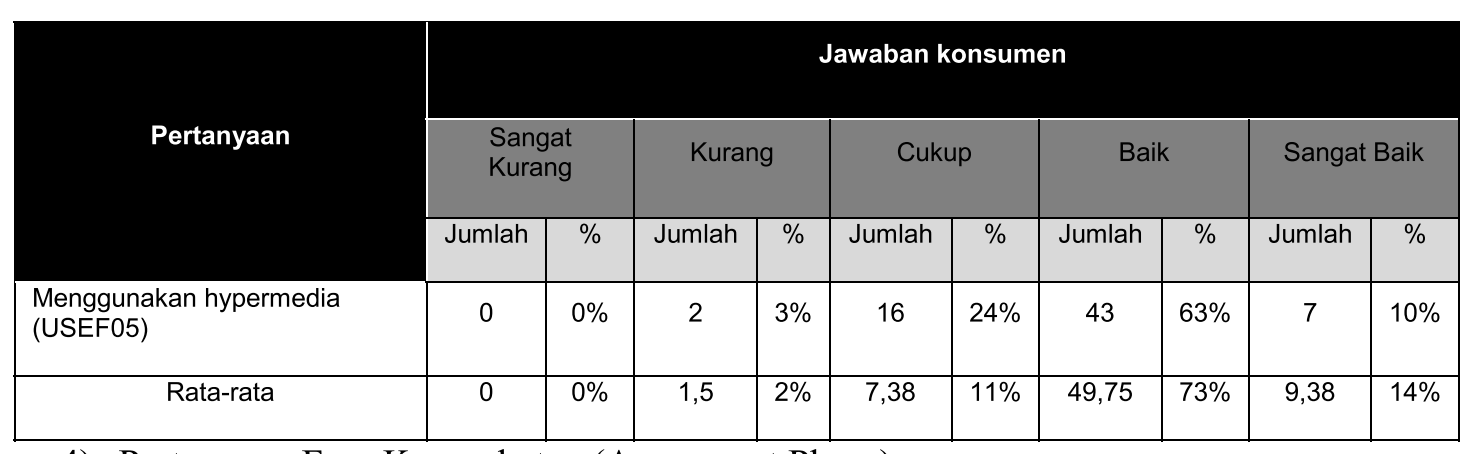

4) Pertanyaan Fase Kesepakatan (Agreement Phase)

Berikut ini adalah tabel hasil jawaban untuk Fase Kesepakatan dari konsumen yang terdiri dari 2 (dua) pertanyaan.

Tabel 5. Hasil Jawaban Fase Kesepakatan

\begin{tabular}{|l|c|c|c|c|c|c|c|c|c|c|}
\hline \multicolumn{7}{|c|}{ Jawaban konsumen } \\
\multicolumn{1}{|c|}{ Pertanyaan } & \multicolumn{2}{|c|}{ Sangat Kurang } & Kurang & \multicolumn{2}{c|}{ Cukup } & \multicolumn{2}{c|}{ Baik } & \multicolumn{2}{c|}{ Sangat Baik } \\
\cline { 2 - 13 } & Jumlah & $\%$ & Jumlah & $\%$ & Jumlah & $\%$ & Jumlah & $\%$ & Jumlah & $\%$ \\
\hline $\begin{array}{l}\text { Sistem pada prosedur } \\
\text { pemesanan (EOU05) }\end{array}$ & 0 & $0 \%$ & 1 & $1 \%$ & 6 & $9 \%$ & 46 & $68 \%$ & 15 & $22 \%$ \\
\hline $\begin{array}{l}\text { Model-model dan metode- } \\
\text { metode penetapan harga } \\
\text { (USEF06) }\end{array}$ & 0 & 0 & 1 & $1 \%$ & 6 & $9 \%$ & 53 & $78 \%$ & 8 & $12 \%$ \\
\hline \multicolumn{1}{|c|}{ Rata-rata } & 0 & $0 \%$ & 1 & $1 \%$ & 6,00 & $9 \%$ & 49,50 & $73 \%$ & 11,50 & $17 \%$ \\
\hline
\end{tabular}

5) Pertanyaan Fase penyelesaian (settlement phase)

Berikut ini adalah tabel hasil jawaban untuk Fase penyelesaian dari konsumen yang terdiri dari 3 (tiga) pertanyaan.

Tabel 6. Hasil Jawaban penyelesaian (settlement phase)

\begin{tabular}{|l|c|c|c|c|c|c|c|c|c|c|}
\hline \multicolumn{7}{|c|}{ Jawaban konsumen } \\
\multicolumn{2}{|c|}{ Pertanyaan } & \multicolumn{2}{c|}{ Sangat Kurang } & \multicolumn{2}{c|}{ Kurang } & \multicolumn{2}{c|}{ Cukup } & \multicolumn{2}{c|}{ Baik } & \multicolumn{2}{c|}{ Sangat Baik } \\
\cline { 2 - 12 } & Jumlah & $\%$ & Jumlah & $\%$ & Jumlah & $\%$ & Jumlah & $\%$ & Jumlah & $\%$ \\
\hline $\begin{array}{l}\text { Integrasi dari layanan-layanan } \\
\text { umum (EOU06) }\end{array}$ & 45 & $66 \%$ & 23 & $34 \%$ & 0 & $0 \%$ & 0 & $0 \%$ & 0 & $0 \%$ \\
\hline $\begin{array}{l}\text { Integrasi dari aplikasi-aplikasi } \\
\text { E-commerce (USEF07) }\end{array}$ & 18 & $26 \%$ & 24 & $35 \%$ & 26 & $38 \%$ & 0 & $0 \%$ & 0 & $0 \%$ \\
\hline $\begin{array}{l}\text { Penelusuran dan perutean } \\
\text { terhadap integrasi layanan } \\
\text { umum dan aplikasi e- } \\
\text { commerce (USEF08) }\end{array}$ & 0 & $0 \%$ & 0 & $0 \%$ & 8 & $12 \%$ & 48 & $71 \%$ & 12 & $18 \%$ \\
\hline \multicolumn{1}{c}{ Rata-rata } & 21 & $31 \%$ & 15,67 & $23 \%$ & 11,33 & $17 \%$ & 16,00 & $24 \%$ & 4,00 & $6 \%$ \\
\hline
\end{tabular}


6) Pertanyaan Fase Setelah Penjualan (After Sale Phase)

Berikut ini adalah tabel hasil jawaban untuk Fase Setelah Penjualan dari konsumen yang terdiri dari 2 (dua) pertanyaan.

Tabel 7. Hasil Jawaban Fase Setelah Penjualan

\begin{tabular}{|c|c|c|c|c|c|c|c|c|c|c|}
\hline \multirow{3}{*}{ Pertanyaan } & \multicolumn{10}{|c|}{ Jawaban konsumen } \\
\hline & \multicolumn{2}{|c|}{$\begin{array}{l}\text { Sangat } \\
\text { Kurang }\end{array}$} & \multicolumn{2}{|c|}{ Kurang } & \multicolumn{2}{|c|}{ Cukup } & \multicolumn{2}{|c|}{ Baik } & \multicolumn{2}{|c|}{ Sangat Baik } \\
\hline & Jumlah & $\%$ & Jumlah & $\%$ & Jumlah & $\%$ & Jumlah & $\%$ & Jumlah & $\%$ \\
\hline $\begin{array}{l}\text { Akses kepada dukungan } \\
\text { pelanggan (EUO07) }\end{array}$ & 0 & $0 \%$ & 8 & $12 \%$ & 14 & $21 \%$ & 30 & $44 \%$ & 16 & $24 \%$ \\
\hline $\begin{array}{l}\text { Kinerja dari dukungan } \\
\text { pelanggan (USEF09) }\end{array}$ & 0 & $0 \%$ & 6 & $9 \%$ & 12 & $18 \%$ & 35 & $51 \%$ & 15 & $22 \%$ \\
\hline Rata-rata & 0 & $0 \%$ & 7,00 & $10 \%$ & 13,00 & $19 \%$ & 32,50 & $48 \%$ & 15,50 & $23 \%$ \\
\hline
\end{tabular}

7) Pertanyaan Fase Komponen Komunitas (Community Component)

Berikut ini adalah tabel hasil jawaban untuk Komponen Komunitas dari konsumen yang terdiri dari 2 (dua) pertanyaan.

Tabel 7. Hasil Jawaban Fase Komponen Komunitas

\begin{tabular}{|l|c|c|c|c|c|c|c|c|c|c|}
\hline \multirow{2}{*}{ Pertanyaan } & \multicolumn{7}{|c||}{ Jawaban konsumen } \\
\cline { 2 - 12 } & \multicolumn{2}{|c|}{ Sangat Kurang } & \multicolumn{2}{|c|}{ Kurang } & \multicolumn{2}{c|}{ Cukup } & \multicolumn{2}{|c|}{ Baik } & \multicolumn{2}{c|}{ Sangat Baik } \\
\cline { 2 - 12 } & Jumlah & $\%$ & Jumlah & $\%$ & Jumlah & $\%$ & Jumlah & $\%$ & Jumlah & $\%$ \\
\hline $\begin{array}{l}\text { Menyediakan link komunitas } \\
\text { pada web }\end{array}$ & 45 & $66 \%$ & 17 & $25 \%$ & 6 & $9 \%$ & 0 & $0 \%$ & 0 & $0 \%$ \\
\hline $\begin{array}{l}\text { Adanya keuntungan yang } \\
\text { diperoleh dari komunitas }\end{array}$ & 42 & $62 \%$ & 17 & $25 \%$ & 9 & $13 \%$ & 0 & $0 \%$ & 0 & $0 \%$ \\
\hline \multicolumn{1}{|c|}{ Rata-rata } & 43,5 & $64 \%$ & 17,00 & $25 \%$ & 7,50 & $11 \%$ & 0,00 & $0 \%$ & 0,00 & $0 \%$ \\
\hline
\end{tabular}

8) Pertanyaan Final Section

Berikut ini adalah tabel hasil jawaban untuk Komponen Komunitas dari konsumen yang terdiri dari 5 (lima) pertanyaan.

Tabel 8. Hasil Jawaban Fase Komponen Komunitas 


\begin{tabular}{|l|c|c|c|c|c|c|c|c|c|c|}
\hline & \multicolumn{2}{|c|}{ Sangat Kurang } & \multicolumn{2}{c|}{ Kurang } & \multicolumn{2}{c|}{ Cukup } & \multicolumn{2}{c|}{ Baik } & \multicolumn{2}{c|}{ Sangat Baik } \\
\cline { 2 - 12 } & Jumlah & $\%$ & Jumlah & $\%$ & Jumlah & $\%$ & Jumlah & $\%$ & Jumlah & $\%$ \\
\hline $\begin{array}{l}\text { Ketersediaan Sistem dalam } \\
\text { bertransaksi }\end{array}$ & 0 & $0 \%$ & 2 & $3 \%$ & 14 & $21 \%$ & 35 & $51 \%$ & 17 & $25 \%$ \\
\hline $\begin{array}{l}\text { Desain dari antarmuka } \\
\text { pengguna }\end{array}$ & 0 & $0 \%$ & 11 & $16 \%$ & 29 & $43 \%$ & 24 & $35 \%$ & 4 & $6 \%$ \\
\hline $\begin{array}{l}\text { Effsiensi waktu dalam } \\
\text { bertransaksi }\end{array}$ & 0 & $0 \%$ & 5 & $7 \%$ & 22 & $32 \%$ & 30 & $44 \%$ & 11 & $16 \%$ \\
\hline $\begin{array}{l}\text { Terdapat fungsi personalisasi } \\
\text { pengguna }\end{array}$ & 0 & $0 \%$ & 13 & $19 \%$ & 23 & $34 \%$ & 24 & $35 \%$ & 8 & $12 \%$ \\
\hline Legalitas web dapat dipercaya & 0 & $0 \%$ & 0 & $0 \%$ & 5 & $7 \%$ & 36 & $53 \%$ & 27 & $40 \%$ \\
\hline \multicolumn{1}{|c|}{ Rata-rata } & 0 & $0 \%$ & 6,20 & $9 \%$ & 18,60 & $27 \%$ & 29,80 & $44 \%$ & 13,40 & $20 \%$ \\
\hline
\end{tabular}

\section{b. Analisa Data}

\section{1) Evaluasi Kategori Fase}

a) Fase Informasi (Information Phase)

Dari tabel 4 dapat diperoleh bahwa untuk fase informasi web abadigrosir.com sudah memberikan layanan informasi yang baik. Rata-rata untuk 8 (delapan) pertanyaan berkaitan dengan informasi web adalah 73\% dari 68 konsumen menyatakan layanan informasi web abadigrosir.com sudah baik, 14\% dari 68 konsumen menyatakan layanan informasi web abadigrosir.com sangat baik, $11 \%$ dari 68 konsumen menyatakan cukup, dan 2\% dari 68 konsumen menyatakan kurang baik.

b) Fase Kesepakatan (Agreement Phase)

Pada fase kesepakatan, abadigrosir.com memiliki penilaian yang baik dari konsumen, system pemesanan dan penerapan metode serta model penetapan harga dinilai baik oleh konsumen, dengan nilai adalah dari 68 konsumen yang menjawab, sebanyak 68\% konsumen menyatakan sistem pada prosedur pemesanan abadigrosir.com sudah baik, sedangkan yang menyatakan kurang baik hanya 1\% dari 68 konsumen yang menjawab.

c) Fase penyelesaian (settlement phase)

Pada fase penyelesaian (settlement phase), abadigrosir.com memiliki penilaian yang kurang baik untuk integrasi layanan-layanan umum (pembayaran menggunakan kartu kredit dan debit master card/visa), dari 68 konsumen yang menjawab, terdapat $66 \%$ yang menyatakan sangat kurang, dan 34\% kurang, artinya seluruh konsumen yang menjawab menyatakan pelayan integrasi layanan umum abadigrosir.com tidak baik atau dengan kata lain bahwa konsumen abdigrosir.com mengharapkan adanya integrasi layanan umum pada tahap pembayaran.

Pada pertanyaan untuk integrasi aplikasi E-Commerce, sebanyak 38\% konsumen menyatakan cukup, sedangkan 35\% menyatakan kurang, dan 26\% menyatakan sangat kurang. Hal ini dapat diartikan bahwa pelayanan penerapan aplikasi e-commerce pada abadigrosir.com masih kurang karena 
dari 68 konsumen yang menjawab terdapat $61 \%$ konsumen yang menyatakan kurang dan sangat kurang.

Sedangkan untuk petanyaan penelusuran dan perutean terhadap integrase layanan umum dan aplikasi e-commerce (ketertelusuran informasi pengiriman barang), dari 68 konsumen yang menjawab terdapat $71 \%$ konsumen yang menyatakan baik, $18 \%$ menyatakan sangat baik, dan $12 \%$ menyatakan cukup. Hal ini menandai bahwa abadigrosir.com telah memberikan pelayanan informasi terhadap ketertulusan transaksi mulai dari persiapan barang sampai dengan pengiriman.

d) Fase Setelah Penjualan (After Sale Phase)

Pada fase setelah penjualan, konsumen memberikan penilaian yang baik terhadap akses dukungan pelanggan dan kinerja dari dukungan pelanggan yang diberikan abadigrosir.com terhadap konsumen, yaitu memiliki rata-rata penilaian sebesar $48 \%$ untuk pernyataan baik dan $23 \%$ untuk pernyataan sangat baik, sehingga dapat disimpulkan bahwa sebanyak $71 \%$ dari 68 konsumen yang menjawab menyatakan penilaian baik untuk pelayanan setelah penjualan yang dilakukan oleh abadigrosir.com.

e) Fase Komponen Komunitas (Community Component)

Pada Fase komponen komunitas abadigrosir.com memperoleh penilaian yang sangat kurang, dari 68 konsumen yang menjawab, terdapat $66 \%$ konsumen yang menyatakan sangat kurang dan $25 \%$ konsumen yang menyatakan kurang terhadap pertanyaan penyediaan link komunitas pada web. Sehingga dapat disimpulkan bahwa sebanyak 91\% dari 68 konsumen yang menjawab, menyatakan webabadigrosir.com sangat kurang dalam menyediakan link komunitas pada web.

Begitupun untuk pertanyaan adanya keuntungan yang diperoleh dari komunitas, dari 68 konsumen yang menjawab, terdapat $62 \%$ konsumen yang menyatakan sangat kurang dan $25 \%$ konsumen yang menyatakan kurang.

\section{f) Final Section}

Pada fase pertanyaan final section memilik keberagaman penilaian diantaranya

- Untuk pertanyaan ketersediaan sistem dalam bertransaksi konsumen menilai abadigrosir telah cukup baik dalam memberikan pelayanan ketersediaan sistem dalam bertransakasi, yaitu sebesar 51\% dari 68 konsumen menyatakan baik dan $25 \%$ menyatakan sangat baik.

- Untuk desain dari antarmuka pengguna abadigrosir.com memperoleh penilaian cukup baik yaitu dari 68 konsumen yang menjawab pertanyaan, sebanyak $43 \%$ menyatakan cukup, sebanyak $35 \%$ menyatakan baik.

- Untuk effsiensi waktu dalam bertransaksi, abadigrosir.com memperoleh penilaian yang baik yaitu dari 68 konsumen yang menjawab pertanyaan, sebanyak 44\% menyatakan baik, sebanyak 32\% menyatakan cukup

- Sedangkan untuk fungsi personalisasi pengguna, abadigrosir.com memperoleh penilaian cukup beragam yaitu dari 68 konsumen yang menjawab pertanyaan, sebanyak $35 \%$ menyatakan baik, sebanyak $34 \%$ menyatakan menyatakan cukup, 19\% menyatakan sangat kurang, dan $12 \%$ menyatakan sangat baik. Hal ini dapat disimpulkan bahwa setiap konsumen memiliki pandangan berbeda terhadap kebutuhan personalisasi pada web abadigrosir.com 
- Penilaian terhadap legalitas abadigrosir.com tidak dapat diragukan lagi, hal ini terbukti dari 68 konsumen yang menjawab sebanyak 44\% konsumen menyatakan legalitas abadigrosir baik, dan 20\% menyatakan sangat baik, serta $27 \%$ menyatakan cukup.

\section{2) Evaluasi EWAM}

Pada evaluasi EWAM pertanyaan yang diajukan kepada pelanggan dibagi kedalam beberapa kategori yaitu kategori Usefullnes Criteria, Easy Of Use Criteria dan Trust Criteria

\section{a) Usefullnes Criteria}

Berikut ini adalah tabel hasil jawaban untuk Usefullnes Criteria dari konsumen yang terdiri dari 8 (delapan) pertanyaan.

Tabel 9. Hasil Jawaban untuk Usefullnes Criteria

\begin{tabular}{|c|c|c|c|c|c|c|c|c|c|c|}
\hline \multirow{3}{*}{ Pertanyaan } & \multicolumn{10}{|c|}{ Jawaban konsumen } \\
\hline & \multicolumn{2}{|c|}{$\begin{array}{l}\text { Sangat } \\
\text { Kurang }\end{array}$} & \multicolumn{2}{|c|}{ Kurang } & \multicolumn{2}{|c|}{ Cukup } & \multicolumn{2}{|c|}{ Baik } & \multicolumn{2}{|c|}{ Sangat Baik } \\
\hline & Jumlah & $\%$ & Jumlah & $\%$ & Jumlah & $\%$ & Jumlah & $\%$ & Jumlah & $\%$ \\
\hline $\begin{array}{l}\text { Kemudahan dalam mengakses } \\
\text { halaman/URL web (EOU01) }\end{array}$ & 0 & $0 \%$ & 3 & $4 \%$ & 9 & $13 \%$ & 41 & $60 \%$ & 15 & $22 \%$ \\
\hline $\begin{array}{l}\text { Kemudahan dalam mengakses } \\
\text { informasi produk yang } \\
\text { ditawarkan (EOU02) }\end{array}$ & 0 & $0 \%$ & 1 & $1 \%$ & 5 & $7 \%$ & 49 & $72 \%$ & 13 & $19 \%$ \\
\hline $\begin{array}{l}\text { Susunan stuktur konten/isi } \\
\text { (EOU03) }\end{array}$ & 0 & $0 \%$ & 1 & $1 \%$ & 6 & $9 \%$ & 52 & $76 \%$ & 9 & $13 \%$ \\
\hline $\begin{array}{l}\text { Sistem pada prosedur } \\
\text { pemesanan (EOU04) }\end{array}$ & 0 & $0 \%$ & 1 & $1 \%$ & 6 & $9 \%$ & 46 & $68 \%$ & 15 & $22 \%$ \\
\hline $\begin{array}{l}\text { Integrasi dari layanan-layanan } \\
\text { umum (EOU05) }\end{array}$ & 45 & $66 \%$ & 23 & $34 \%$ & 0 & $0 \%$ & 0 & $0 \%$ & 0 & $0 \%$ \\
\hline $\begin{array}{l}\text { Akses kepada dukungan } \\
\text { pelanggan (EUO06) }\end{array}$ & 0 & $0 \%$ & 8 & $12 \%$ & 14 & $21 \%$ & 30 & $44 \%$ & 16 & $24 \%$ \\
\hline $\begin{array}{l}\text { Ketersediaan Sistem dalam } \\
\text { bertransaksi }\end{array}$ & 0 & $0 \%$ & 2 & $3 \%$ & 14 & $21 \%$ & 35 & $51 \%$ & 17 & $25 \%$ \\
\hline $\begin{array}{l}\text { Desain dari antarmuka } \\
\text { pengguna }\end{array}$ & 0 & $0 \%$ & 11 & $16 \%$ & 29 & $43 \%$ & 24 & $35 \%$ & 4 & $6 \%$ \\
\hline Rata-rata & 5,63 & $8 \%$ & 6,25 & $9 \%$ & 10,38 & $15 \%$ & 34,63 & $51 \%$ & 11,13 & $16 \%$ \\
\hline
\end{tabular}

Berdasarkan tabel 9, penilaian konsumen terhadap usefulness Criteria pada web abadigrosir.com hasilnya adalah baik, hal ini dapat dilihat dari nilai ratarata yang diperoleh dari 8 (delapan) pertanyaan, yaitu sebanyak $51 \%$ konsumen menyatakan baik, 16\% konsumen menyatakan sangat baik, 15\% konsumen menyatakan cukup, 9\% konsumen menyatakan kurang, dan $8 \%$ konsumen menyatakan kurang. Penilaian cukup baik ini diperoleh dari berberapa pertanyaan yaitu 
- Kemudahan dalam mengakses halaman/URL web sebanyak $60 \%$.

- Kemudahan dalam mengakses informasi produk yang ditawarkan sebanyak $72 \%$.

- Susunan stuktur konten/isi sebanyak $76 \%$.

- Sistem pada prosedur pemesanan sebanyak $68 \%$.

- Akses kepada dukungan pelanggan sebanyak $44 \%$.

- Ketersediaan Sistem dalam bertransaksi sebanyak 51\%.

Namun terdapat penilaian 2 (dua) pertanyaan yang tidak memperoleh penilaian baik. Adapun 2 (dua) pertanyaan tersebut adalah :

- Integrasi dari layanan-layanan umum memperoleh penilaian $66 \%$ sangat kurang, dan $44 \%$ memperoleh penilaian kurang. Hal ini menandakan konsumen menginginkan web abadigrosir memiliki integrase layanan-layanan umum untuk memudahkan dalam bertransaksi di web abadigrosir.com

- Desain dari antarmuka pengguna memperoleh penilaian yang beragam, namun yang paling besar adalah penilaian penyataan cukup sebanyak $43 \%$, dan baik sebanyak 35\%. Hal ini menandakan bahwa konsumen menginginkan web abadigrosir.com meningkatkan desain antar muka pengguna, agar kosumen lebih nyaman dan memudahkan dalam bertransaksi.

\section{b) Easy Of Use Criteria}

Berikut ini adalah tabel hasil jawaban untuk Easy Of Use Criteria dari konsumen yang terdiri dari 13 (tiga belas) pertanyaan.

Tabel 10. Hasil Jawaban untuk Easy Of Use Criteria

\begin{tabular}{|l|c|c|c|c|c|c|c|c|c|c|}
\hline \multirow{2}{*}{ Pertanyaan } & \multicolumn{7}{c|}{ Jawaban konsumen } \\
\cline { 2 - 13 } & \multicolumn{2}{c|}{$\begin{array}{c}\text { Sangat } \\
\text { Kurang }\end{array}$} & \multicolumn{2}{c|}{ Kurang } & \multicolumn{2}{c|}{ Cukup } & \multicolumn{2}{c|}{ Baik } & \multicolumn{2}{c|}{ Sangat Baik } \\
\cline { 2 - 13 } & Jumlah & $\%$ & Jumlah & $\%$ & Jumlah & $\%$ & Jumlah & $\%$ & Jumlah & $\%$ \\
\hline $\begin{array}{l}\text { Kuantitas Informasi produk dan } \\
\text { lainnya (USEF01) }\end{array}$ & 0 & $0 \%$ & 1 & $1 \%$ & 5 & $7 \%$ & 55 & $81 \%$ & 7 & $10 \%$ \\
\hline $\begin{array}{l}\text { Menyampaikan harga produk } \\
\text { yang ditawarkan (USEF02) }\end{array}$ & 0 & $0 \%$ & 1 & $1 \%$ & 6 & $9 \%$ & 52 & $76 \%$ & 9 & $13 \%$ \\
\hline $\begin{array}{l}\text { Pembundelan produk-produk } \\
\text { dan layanan-layanan } \\
\text { (USEF03) }\end{array}$ & 0 & $0 \%$ & 1 & $1 \%$ & 6 & $9 \%$ & 53 & $78 \%$ & 8 & $12 \%$ \\
\hline $\begin{array}{l}\text { Sistem-sistem rekomendasi } \\
\text { (USEF04) }\end{array}$ & 0 & $0 \%$ & 2 & $3 \%$ & 6 & $9 \%$ & 53 & $78 \%$ & 7 & $10 \%$ \\
\hline $\begin{array}{l}\text { Menggunakan hypermedia } \\
\text { (USEF05) }\end{array}$ & 0 & $0 \%$ & 2 & $3 \%$ & 16 & $24 \%$ & 43 & $63 \%$ & 7 & $10 \%$ \\
\hline $\begin{array}{l}\text { Model-model dan metode- } \\
\text { metode penetapan harga } \\
\text { (USEF06) }\end{array}$ & 0 & 0 & 1 & $1 \%$ & 6 & $9 \%$ & 53 & $78 \%$ & 8 & $12 \%$ \\
\hline $\begin{array}{l}\text { Integrasi dari aplikasi-aplikasi } \\
\text { E-commerce (USEF07) }\end{array}$ & 18 & $26 \%$ & 24 & $35 \%$ & 26 & $38 \%$ & 0 & $0 \%$ & 0 & $0 \%$ \\
\hline
\end{tabular}




\begin{tabular}{|c|c|c|c|c|c|c|c|c|c|c|}
\hline \multirow{3}{*}{ Pertanyaan } & \multicolumn{10}{|c|}{ Jawaban konsumen } \\
\hline & \multicolumn{2}{|c|}{$\begin{array}{l}\text { Sangat } \\
\text { Kurang }\end{array}$} & \multicolumn{2}{|c|}{ Kurang } & \multicolumn{2}{|c|}{ Cukup } & \multicolumn{2}{|c|}{ Baik } & \multicolumn{2}{|c|}{ Sangat Baik } \\
\hline & Jumlah & $\%$ & Jumlah & $\%$ & Jumlah & $\%$ & Jumlah & $\%$ & Jumlah & $\%$ \\
\hline $\begin{array}{l}\text { Penelusuran dan perutean } \\
\text { terhadap integrasi layanan } \\
\text { umum dan aplikasi e- } \\
\text { commerce (USEF08) }\end{array}$ & 0 & $0 \%$ & 0 & $0 \%$ & 8 & $12 \%$ & 48 & $71 \%$ & 12 & $18 \%$ \\
\hline $\begin{array}{l}\text { Kinerja dari dukungan } \\
\text { pelanggan (USEF09) }\end{array}$ & 0 & $0 \%$ & 6 & $9 \%$ & 12 & $18 \%$ & 35 & $51 \%$ & 15 & $22 \%$ \\
\hline $\begin{array}{l}\text { Menyediakan link komunitas } \\
\text { pada web (USEF10) }\end{array}$ & 45 & $66 \%$ & 17 & $25 \%$ & 6 & $9 \%$ & 0 & $0 \%$ & 0 & $0 \%$ \\
\hline $\begin{array}{l}\text { Adanya keuntungan yang } \\
\text { diperoleh dari komunitas } \\
\text { (USEF11) }\end{array}$ & 42 & $62 \%$ & 17 & $25 \%$ & 9 & $13 \%$ & 0 & $0 \%$ & 0 & $0 \%$ \\
\hline $\begin{array}{l}\text { Effsiensi waktu dalam } \\
\text { bertransaksi (USEF12) }\end{array}$ & 0 & $0 \%$ & 5 & $7 \%$ & 22 & $32 \%$ & 30 & $44 \%$ & 11 & $16 \%$ \\
\hline $\begin{array}{l}\text { Terdapat fungsi personalisasi } \\
\text { pengguna (USEF13) }\end{array}$ & 0 & $0 \%$ & 13 & $19 \%$ & 23 & $34 \%$ & 24 & $35 \%$ & 8 & $12 \%$ \\
\hline Rata-rata & 8,08 & $12 \%$ & 6,92 & $10 \%$ & 11,62 & $17 \%$ & 34,31 & $50 \%$ & 7,08 & $10 \%$ \\
\hline
\end{tabular}

Berdasarkan tabel 10, tentang penilaian Easy Of Use Criteria, abadigrosir.com memperoleh penilaian yang baik, hal ini berdasarkan dari 13 pertanyaan yang diajukan kepada konsumen, dengan nilai rata-rata 50\% menyatakan baik, dan $10 \%$ menyatakan sangat baik, serta $17 \%$ menyatakan cukup. Untuk rata-rata penilaian kurang dan sangat kurang masing-masing memperoleh nilai 10\% dan $12 \%$, hali ini dipengaruhi oleh beberpa pertanyaan yang memiliki nilai yang kurang dan sangat kurang.

Pada penilaian baik diperoleh dari beberapa pertanyaan antara lain :

- Kuantitas Informasi produk dan lainnya sebanyak $81 \%$

- Menyampaikan harga produk yang ditawarkan sebanyak $76 \%$

- Pembundelan produk-produk dan layanan-layanan sebanyak $78 \%$

- Sistem-sistem rekomendasi sebanyak sebanyak $78 \%$

- Menggunakan hypermedia sebanyak $63 \%$

- Model-model dan metode-metode penetapan harga sebanyak 78\%

- Penelusuran dan perutean terhadap integrasi layanan umum dan aplikasi e-commerce sebanyak $71 \%$

- Kinerja dari dukungan pelanggan sebanyak $51 \%$

- Effsiensi waktu dalam bertransaksi sebanyak $44 \%$

- Terdapat fungsi personalisasi pengguna sebanyak $35 \%$

Namun terdapat 3 (tiga) pertanyaan yang memiliki penilaian yang kurang baik diantaranya adalah :

- Integrasi dari aplikasi-aplikasi E-commerce 38\% menyatakan cukup, namun terdapat penilaian kurang dan sangat kurang sebesar $51 \%$

- Menyediakan link komunitas pada web sebanyak $66 \%$ konsumen menyatakan sangat kurang 
- Adanya keuntungan yang diperoleh dari komunitas sebanyak $62 \%$ konsumen menyatakan sangat kurang

c) Trust Criteria

\begin{tabular}{|c|c|c|c|c|c|c|c|c|c|c|}
\hline \multirow{3}{*}{ Pertanyaan } & \multicolumn{10}{|c|}{ Jawaban konsumen } \\
\hline & \multicolumn{2}{|c|}{$\begin{array}{l}\text { Sangat } \\
\text { Kurang }\end{array}$} & \multicolumn{2}{|c|}{ Kurang } & \multicolumn{2}{|c|}{ Cukup } & \multicolumn{2}{|c|}{ Baik } & \multicolumn{2}{|c|}{ Sangat Baik } \\
\hline & Jumlah & $\%$ & Jumlah & $\%$ & Jumlah & $\%$ & Jumlah & $\%$ & Jumlah & $\%$ \\
\hline Legalitas web dapat dipercaya & 0 & $0 \%$ & 0 & $0 \%$ & 5 & $7 \%$ & 36 & $53 \%$ & 27 & $40 \%$ \\
\hline Rata-rata & 0 & $0 \%$ & 0,00 & $0 \%$ & 5,00 & $7 \%$ & 36,00 & $53 \%$ & 27,00 & $40 \%$ \\
\hline
\end{tabular}

Pada bagian kriteria kepercayaan web abadigrosir.com memperoleh penilaian yang baik, dari 68 konsumen, terdapat 53\% menyatakan baik, dan $40 \%$ menyatakan sangat baik.

\section{Kesimpulan dan Saran}

\section{a. Kesimpulan}

Dari hasil pengumpulan jawaban dan analisa tentang penilaian web abadigrosir.com menggunakan metode EWAM, adalah sebagai berikut

1) Pada kriteria kegunaan, konsumen memberikan penilaian yang baik untuk webabadigrosir.com, dengan nilai rata-ratanya yaitu sebanyak $51 \%$ yang menyatakan baik, dan 16\% menyatakan sangat baik.

2) Untuk kriteria mudah digunakan, konsumen memerikan penilaian yang baik dengan nilai rata-ratanya yaitu sebanyak $50 \%$ yang menyatakan baik, dan $10 \%$ menyatakan cukup.

3) Sedangkan kiteria kepercayaan, konsumen memberikan penilaian yang dominan, dimana konsumen sangat mempercayai legalitas daripada web abadigrosir.com yaitu sebanyak 53\% konsumen menyatakan baik, dan 40\% menyatakan sangat baik.

\section{b. Saran}

Dari hasil evaluasi web abadigrosir.com menggunakan metode EWAM, terdapat berberap saran untuk web abadigrosir.com agar dapat meningkatkan kinerja daripada web abadigrosir.com, yaitu

1) Adanya integrase layanan-layanan e-commerce yang mendukung transaksi di web abadigrosir.com

2) Tersedianya link komunitas konsumen web abadigrosir.com, agar konsumen bias saling berbagi informasi tentang produk yang dibutuhkan oleh konsumen, hal ini pun dapat digunakan oleh abadigrosir.com untuk mengetahui kebutuhankebutuhan konsumennya.

3) Desain antar muka memiliki tampilan yang interaktif yang dapat menarik perhatian dari pada konsumen 


\section{DAFTAR PUSTAKA}

[1] Susilo, Andi (2010). Evaluasi Aplikasi E-Commerce Menggunakan Etend WebAssessment Method (EWAM) dari Perspektif Konsumen: Studi Kasus Toko Buku Online di Indonesia. Thesis. Unversitas Respati Indonesia.

[2] Insani, E. P. (2013). Analisis Pengaruh Kenyamanan Terhadap Minat Beli Secara Online Pada Pemesanan Tiket Kereta Api Melalui Website Resmi PT. KAI. Jurnal Sains Pemasaran Indonesia, 241-260.

[3] Pratama, I. A. (2005). E-Commerce, E-Bussines, dan Mobile E-Commerce Berbasiskan Open Source. Bandung: Informatika.

[4] Schubert, P. (2003). Extended Web Assessment Method (EWAM)-Evaluation of Electronic Commerce Applications from the Customer's Viewpoint, in: International Journal of Electronic Commerce, Vol. 7, No. 2, Winter 2002-2003.

[5] Suki, N.B.M., 2005, Motivation and Concern Factors for Internet Shopping : A Malaysian Perspective, Retrieved October 9, 2013

[1] Yin (2003). Case Study Research: Design and Methods, Third Edition. Sage Publications, Inc. 2455 Teller Road Thousand Oaks, California 91320 